\title{
Assessment of disease activity in inflammatory bowel disease: a new approach using "'In granulocyte scanning
}

\author{
S H SAVERYMUTTU, J P LAVENDER， H J F HODGSON， V S CHADWICK
}

\begin{abstract}
"11 In leucocyte scanning yields images of diseased bowel in patients with inflammatory bowel disease. The technique has recently been improved by being made more specific for acute inflammation by the isolation and labelling of a pure granulocyte preparation. The value of ${ }^{111}$ In granulocyte scanning in monitoring response to steroid treatment was assessed in 22 patients with Crohn's disease or ulcerative colitis. After steroid treatment there was agreement between the change in the scan grade and the change in clinical disease activity in 18 of the 22 patients. Overall there was a significant correlation between the change in the scan grade and clinical improvement $(r=0.775, p<0.001)$.

This study suggests that ${ }^{111}$ In granulocyte scanning can provide a rapid assessment of disease activity in inflammatory bowel disease.
\end{abstract}

\section{Introduction}

Drug treatment of inflammatory bowel disease is hard to evaluate because of the difficulty in assessing inflammatory activity. ${ }^{1}$ Laboratory variables of inflammation, such as the erythrocyte sedimentation rate and $\mathrm{C}$ reactive protein and orosomucoid concentrations, are indirect and not specific for inflammation of the gut; thus they may be altered by extraintestinal complications or intercurrent illnesses. Direct assessment of the degree of bowel inflammation by radiological examination is an attractive approach for the clinician. Studies in both Crohn's disease ${ }^{2} 3$ and ulcerative colitis, ${ }^{4}$ however, have been disappointing, showing poor correlations between radiological

Department of Medicine, Royal Postgraduate Medical School, Hammersmith Hospital, London W12 OHS

$S$ H SAVERYMUTTU, MRCP, research fellow

H J F HODGSON, DM, FRCP, consultant physician

V S CHADWICK, MD, FRCP, consultant physician

Department of Radiology, Royal Postgraduate Medical School J P LAVENDER, FRCR, FRCPED, consultant radiologist

Correspondence to: Dr S H Saverymuttu, Department of Gastroenterology, Hammersmith Hospital, Du Cane Road, London W12 OHS. changes and response to drug treatment. Furthermore, recent studies have shown that considerable histological activity may be present-for example, in the colon-in the absence of radiological changes. ${ }^{5} \cdot$

111In leucocyte scanning has been used as an alternative to radiological examination for imaging inflammatory bowel disease $^{7-9}$ and in principle should accurately show inflammatory activity. Recently, this technique has been made more specific for the acute inflammatory response by the isolation and labelling of a pure preparation of granulocytes distinct from lymphocytes and platelets. ${ }^{10}$ In this study we assessed the value of ${ }^{11}$ In granulocyte scanning in monitoring the response of active inflammatory bowel disease to steroid treatment.

\section{Patients and methods}

Twenty two patients with active inflammatory bowel disease (Crohn's disease or ulcerative colitis) were studied before and after treatment with prednisolone $30-40 \mathrm{mg}$ daily. The median duration of treatment was six weeks (range two to 16 weeks). Patients filled in a diary card, and a disease activity index was calculated ${ }^{11}$ using the

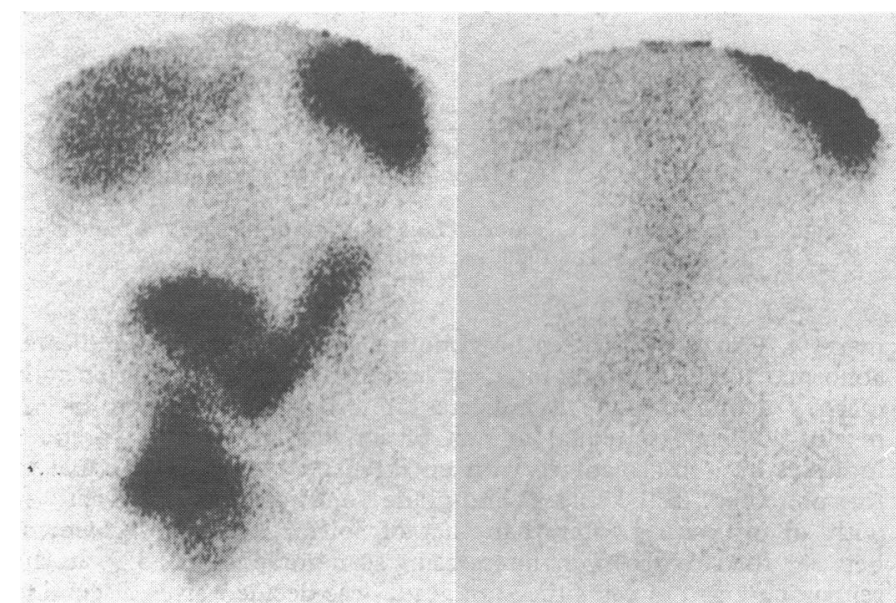

FIG 1-111 In leucocyte scans in case 2. Left: Before treatment, showing grade 3 activity in distal colon. Right: Normal scan after six weeks' steroid treatment. 
weighting factors derived in the National Co-operative Crohn's Disease Study. ${ }^{12}$

To avoid variations in the proportions of ${ }^{111}$ In on the leucocyte, red cell, and platelet fractions a pure granulocyte preparation was separated out and labelled with ${ }^{111}$ In tropolonate ${ }^{10}$ without being removed from the plasma. The dose of ${ }^{111}$ In injected ranged from 150 to $300 \mu \mathrm{Ci}$. Abdominal scans were performed two to four hours after reinjection of the labelled granulocytes and assessed independently by a nuclear physician and gastroenterologist according to the following grading system, which is based on the normal distribution of labelled cells-that is, with greatest activity in the spleen, intermediate activity in the liver, and least activity in the bone

\section{Results}

Initial and final assessments-Fifteen of the patients studied had Crohn's disease and seven ulcerative colitis (table). Fourteen were women and eight men. In all patients the disease activity index before treatment was greater than 150. Abdominal scans in all patients before treatment showed abnormal activity corresponding to grade 2 or 3 (fig 1 (left)). No patient had activity assessed as grade 4 . After treatment activity scores were below 150 in 12 patients and the scan grade had changed to 0 or 1 in 13 patients. Overall there was a significant correlation between activity score and scan grade $(r=0.72$ $\mathrm{p}<0.001$ ) (fig 2).

Clinical details of patients

\begin{tabular}{|c|c|c|c|c|c|c|c|}
\hline \multirow{2}{*}{ Case No } & \multirow{2}{*}{ Diagnosis } & \multirow{2}{*}{ Distribution of disease } & \multicolumn{3}{|c|}{ Disease activity index } & \multicolumn{2}{|c|}{ Scan grade } \\
\hline & & & Initially & Finally & Decrease & Initially & Finally \\
\hline $\begin{array}{r}1 \\
2 \\
3 \\
4 \\
5 \\
6 \\
7 \\
8 \\
9 \\
10 \\
11 \\
12 \\
13 \\
14 \\
15 \\
16 \\
17 \\
18 \\
19 \\
20 \\
21 \\
22\end{array}$ & $\begin{array}{l}C D \\
U C \\
U C \\
U C \\
U C \\
C D \\
C D \\
C D \\
C D \\
C D \\
C D \\
U C \\
C D \\
U C \\
C D \\
C D \\
C D \\
C D \\
C D \\
C D \\
C D \\
U C\end{array}$ & $\begin{array}{l}\text { Ileal } \\
\text { Distal colon } \\
\text { Pancolitis } \\
\text { Pancolitis } \\
\text { Pancolitis } \\
\text { Ileal } \\
\text { Ileal } \\
\text { Ileocolonic } \\
\text { Pancolitis } \\
\text { Pancolitis } \\
\text { Pancolitis } \\
\text { Distal colon } \\
\text { Ileal } \\
\text { Pancolitis } \\
\text { Ileal } \\
\text { Pancolitis } \\
\text { Pancolitis } \\
\text { Ileal } \\
\text { Ileal } \\
\text { Pancolitis } \\
\text { Pancolitis } \\
\text { Pancolitis }\end{array}$ & $\begin{array}{l}250 \\
305 \\
323 \\
320 \\
240 \\
241 \\
239 \\
184 \\
250 \\
160 \\
348 \\
327 \\
331 \\
307 \\
278 \\
242 \\
256 \\
202 \\
202 \\
249 \\
312 \\
320\end{array}$ & $\begin{array}{r}46 \\
102 \\
40 \\
141 \\
43 \\
130 \\
90 \\
106 \\
70 \\
47 \\
182 \\
192 \\
232 \\
175 \\
103 \\
160 \\
230 \\
187 \\
101 \\
157 \\
296 \\
272\end{array}$ & $\begin{aligned} 204 \\
203 \\
283 \\
179 \\
179 \\
111 \\
149 \\
78 \\
180 \\
113 \\
166 \\
135 \\
99 \\
132 \\
175 \\
82 \\
26 \\
15 \\
101 \\
92 \\
16 \\
48\end{aligned}$ & $\begin{array}{l}3 \\
3 \\
3 \\
3 \\
3 \\
3 \\
3 \\
3 \\
2 \\
3 \\
3 \\
3 \\
2 \\
3 \\
3 \\
3 \\
3 \\
3 \\
2 \\
3 \\
3 \\
3\end{array}$ & $\begin{array}{l}0 \\
0 \\
0 \\
0 \\
0 \\
1 \\
1 \\
1 \\
0 \\
1 \\
1 \\
1 \\
1 \\
2 \\
3 \\
3 \\
3 \\
3 \\
2 \\
3 \\
3 \\
3\end{array}$ \\
\hline
\end{tabular}

$\mathrm{CD}=$ Crohn's disease

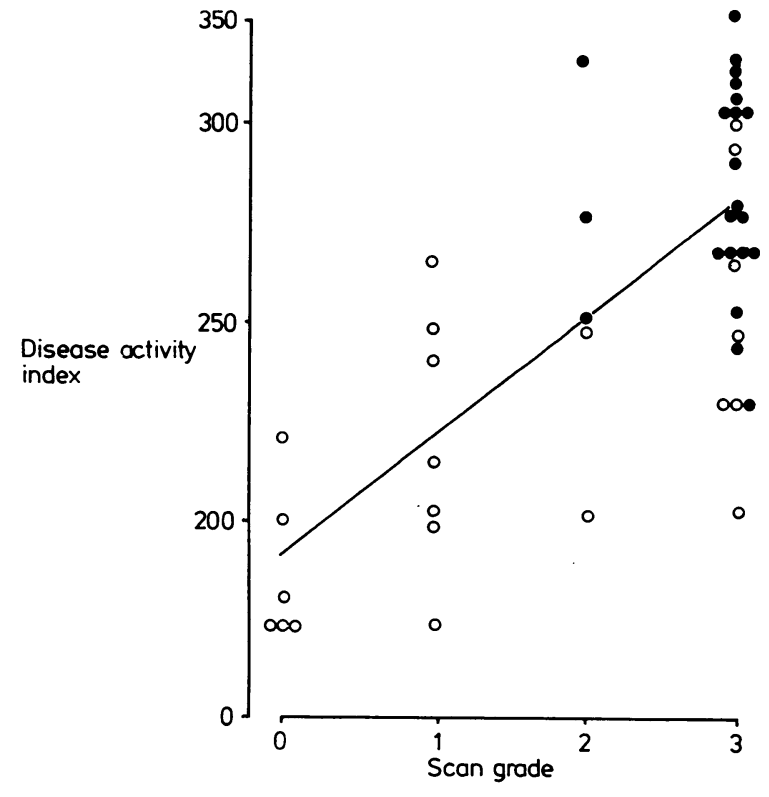

FIG 2-Disease activity index versus scan grade before $(0)$ and after $(O)$ treatment $(r=0.72, p<0.001)$.

marrow. Grade 0 indicates no abnormal activity; grade 1 indicates abnormal activity with an intensity less than or equal to that of bone marrow activity; grade 2 indicates abnormal activity with an intensity less than or equal to that of activity in the liver; grade 3 indicates abnormal activity with an intensity less than or equal to that of activity in the spleen; and grade 4 indicates abnormal activity with an intensity greater than that of splenic activity. Agreement between the two observers in assessing scan grade was $92.5 \%$. In the remaining $7.5 \%$ of cases the scan grade was decided after discussion between the two observers.

Student's $t$ test and linear regression were used for statistical analysis of results.

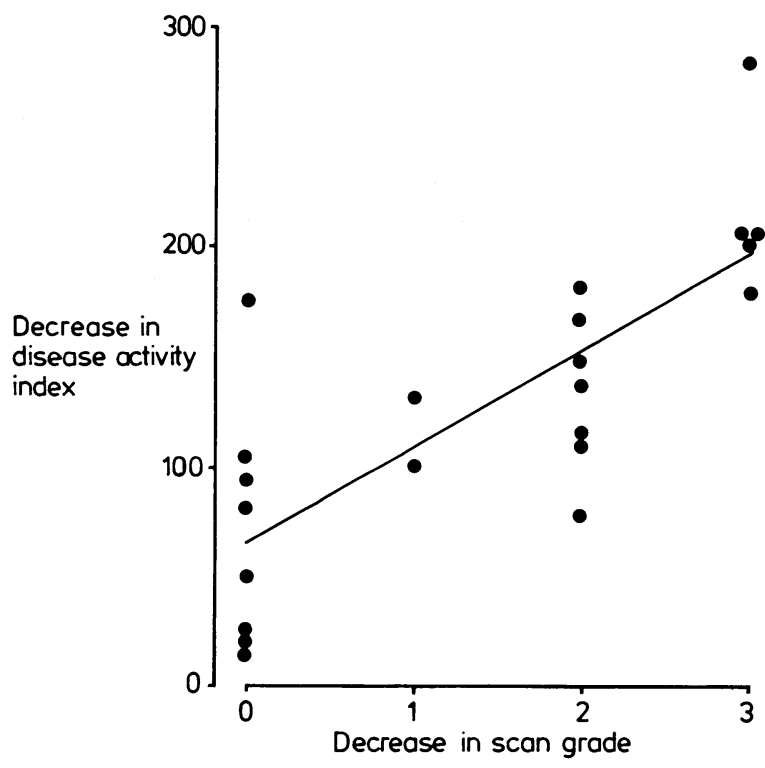

FIG 3-Decreases in disease activity index and scan grade after steroid treatment $(r=0.775, p<0.001)$.

Effect of treatment-After steroid treatment 14 of the patients had improved, their scores of clinical activity having fallen by more than 100 (fig 3). Repeat study showed an improvement in scan grade in 12 of these 14 patients (fig 1); in the remaining two patients there was obvious improvement in the scan but this did not meet the criteria for a change in scan grade (fig 4). In two patients whose scan grade improved after steroid treatment the scores of disease activity fell by 99 and 78 respectively. The remaining six patients showed neither improvement in scan grade nor reduction in activity score by greater than 100 . Overall there was a highly significant correlation between change in scan grade and change in activity index $(r=0.775, p<0.001)$ (fig 3). 


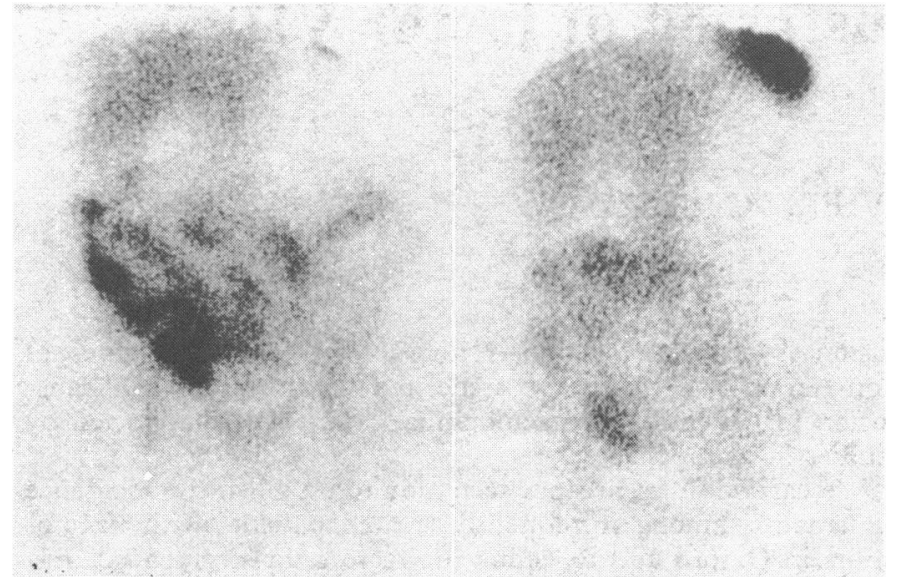

FIG 4-111 In leucocyte scan in case 15. Left: before treatment, showing diffuse grade 3 ileal disease. Right: after two weeks' steroid treatment, showing considerable improvement but still grade 3 activity.

\section{Discussion}

${ }^{111}$ In granulocyte scanning is a logical approach to the problem of assessing disease activity in inflammatory bowel disease. It has important advantages over clinical and laboratory assessments in being both a direct and a specific assessment of bowel inflammation, and it is accurate in determining the extent of disease in colitis ${ }^{71}$ and can detect complicating abscesses. The present work extends the usefulness of studies using labelled granulocyte in the overall assessment of inflammatory bowel disease.

The present technique offers several advantages over mixed leucocyte preparations. A granulocyte preparation allows the dosage of radioactivity to be reduced by up to half by avoiding unwanted red cell, lymphocyte, and platelet contamination, which increases background to target organ activity. Use of ${ }^{111}$ In tropolonate to label granulocytes in plasma permits rapid visualisation of inflammatory sites, ${ }^{13}$ with accurate localisation within three hours after reinjection rather than the 16-24 hours used by other workers. ${ }^{12} 14$ In addition to shortening the time for investigation early scanning avoids the errors in determining disease distribution consequent on delayed scanning, when intraluminal transit of activity has occurred.

A major difficulty in evaluating a new assessment of disease activity in inflammatory bowel disease is the lack of an accepted "gold standard." The Crohn's disease activity index is useful as it is the most widely used clinical assessment against which newer clinical and laboratory assessments have been compared. Since many of the variables that are measured to obtain the index are also major indicators of disease activity in ulcerative colitis it should be applicable to assessing activity in ulcerative colitis." It has certain limitations, however, the most serious being the high subjective element, which may be particularly important when drugs such as steroids with known euphoriant effects are being assessed. Furthermore, factors such as fibrous strictures and bowel resections can raise activity scores and not reflect inflammatory activity. In the present study scanning provided objective support to clinical scoring by showing active disease of grade 2 or more in all 22 patients. Scanning, however, also highlighted the limitations of the disease activity index in defining remission. In six (all with Crohn's disease) of the 12 patients with scores of less than 150 after treatment who therefore met the criteria for clinical remission ${ }^{12}$ scanning showed inflammatory activity of grade 1 or higher. A grade 0 scan is therefore an alternative to the clinical definition of remission. Whether a treatment protocol designed to have an end point of remission on scanning would result in a more prolonged remission is uncertain, but such a policy merits investigation.

Although overall there was a surprisingly high correlation between a change in the scan grade and a change in the disease activity index, the use of only four grades of activity on scans means that small changes in activity cannot be detected. Computer linked analysis might improve the accuracy of the technique, but many centres do not have these extra facilities. An alternative modification is to measure faecal excretion of "11In labelled granulocytes, which gives a more accurate and sensitive assessment of inflammatory activity. ${ }^{18}$ Scanning, however, is rapid and avoids all the problems associated with faecal collection.

${ }^{111}$ In granulocyte scanning has the advantage over both radiological and endoscopic assessment in requiring no bowel preparation, being able to image both the small and large bowels in one examination, and by its safety even in severely ill patients. Furthermore, interpreting such scans is simple as an abnormality represents active inflammation, whereas in radiology it is often difficult to decide whether an abnormality represents active inflammation or chronic changes. These factors have encouraged several centres to use ${ }^{111}$ In leucocyte scanning in inflammatory bowel disease, and already promising results have been reported in both adults ${ }^{16}$ and children. ${ }^{17}$

On the basis of this study we believe that ${ }^{111}$ In labelled granulocytes offer important advantages over the standard mixed leucocyte preparations, and this technique should permit rapid, simple, and precise assessment of disease activity in inflammatory bowel disease.

We are grateful to Amersham International for the supply of ${ }^{111}$ In and to Miss Sally Barnes for secretarial help.

SHS was supported by the Wellcome Trust.

\section{References}

1 Hodgson HJF. Assessment of drug therapy in inflammatory bowel disease. Br f Clin Pharmacol 1982;14:159-70.

${ }^{2}$ Goldberg HI, Caruthers SB, Nelson JA, Singleton JW. Radiographic findings of the National Co-operative Crohn's Disease Study. Gastroenterology $1979 ; 77: 925-37$.

${ }^{3}$ Ursing BO, Alm T, Barany F, et al. A comparative study of metronidazole and sulfasalazine for active Crohn's disease: the co-operative Crohn's disease study in Sweden. Gastroenterology 1982;83:550-62.

4 Truelove S, Witts LJ. Cortisone in ulcerative colitis: final report on a therapeutic trial. $\mathrm{Br}$ Med $\mathcal{F} 1955$;ii:1041-4.

5 Kingham JG, Levison DA, Bell JA, Dawson AM. Microscopic colitis-a cause of chronic watery diarrhoea. $\mathrm{Br} M e d \mathcal{F} 1982 ; 285: 1601-4$.

${ }^{6}$ Elliott PR, Lennard-Jones JE, Bartram CI, et al. Colonoscopic diagnosis of minimal change colitis in patients with a normal sigmoidoscopy and normal air-contrast barium enema. Lancet 1982;i:650-2.

7 Saverymuttu SH, Peters AM, Hodgson HJ, Chadwick VS, Lavender JP. Indium-111 autologous leucocyte scanning: comparison with radiology for imaging the colon in inflammatory bowel disease. $\mathrm{Br} \mathrm{Med} \mathcal{F} 1982$; 285:255-7.

${ }^{8}$ Segal AW, Ensell J, Munro JA, Sarner M. Indium-111-tagged leucocytes in the diagnosis of inflammatory bowel disease. Lancet $1981 ; \mathrm{ii} \cdot 230-2$

- Saverymuttu SH, Peters AM, Lavender JP, Hodgson HJF, Chadwick VS. 111 Indium autologous leucocytes in inflammatory bowel disease. Gut 1983;24:293-9.

${ }^{10}$ Danpure HJ, Osman S, Brady F. The labelling of blood cells in plasma with ${ }^{111}$ In tropolonate. Br $\mathcal{F}$ Radiol 1982;55:247-9.

11 Stein DT, Gray GM, Gregory PB, et al. Location and activity of ulcerative and Crohn's colitis by indium-111 leucocyte scan. Gastroenterology 1983;84:388-93.

12 Best WR, Becktel JM, Singleton JW, Kern F. Development of a Crohn's disease activity index. Gastroenterology 1976;70:439-44.

13 Peters AM, Saverymuttu SH, Danpure HJ, Oxman S, Reavy H, Lavender JP. Imaging inflammation with 111-indium-tropolonate labelled leucocytes. $\mathcal{F}$ Nucl Med 1983;24:39-44.

14 Ascher NZ, Forstrom L, Simmons RL. Radiolabelled autologous leucocyte scanning for abscess detection. World f Surg 1980;4:395-402.

15 Saverymuttu SH, Peters AM, Pepys MB, Lavender JP, Hodgson HJF, Chadwick VS. Quantitative faecal excretion of 111-indium-labelled autologous granulocytes in the assessment of disease activity in Crohn's disease [Abstract]. Gut 1983;23:893.

${ }^{16}$ Buxton-Thomas M, Dickinson RJ, Maltby P, Hunter JO, Wraight EP. Does ${ }^{111}$ indium autologous leucocyte scintigraphy help in the management of patients with chronic inflammatory bowel disease ? Eur $\mathcal{F}$ Nuc Med 1983;8:A80.

17 Vivian G, Milla PJ, Gordon I. The value of ${ }^{11}$ indium WBC scanning in inflammatory bowel disease in childhood. Eur $\mathcal{F}$ Nucl Med 1983;8:A81.

(Accepted 3 October 1983) 